\title{
PERIODONTAL DISEASE - A RISK OF CARDIOVASCULAR DISEASE
}

\author{
P. L. RAVISHANKAR ${ }^{1}$, PRIYANKAR CHAKRABORTY ${ }^{\mathbf{2}} \&$ A. V. SARAVANAN ${ }^{\mathbf{3}}$ \\ ${ }^{I}$ Professor \& H. O. D, Department of Periodontics, SRM Kattankulathur \\ Dental College, Potheri, kanchipuram, Tamil Nadu, India \\ ${ }^{2}$ Post Graduate, Department of Periodontics, SRM Kattankulathur Dental \\ College, Potheri, kanchipuram, Tamil Nadu, India \\ ${ }^{3}$ Reader, Department of Periodontics, SRM Kattankulathur Dental College,
}

Potheri, kanchipuram, Tamil Nadu, India

\begin{abstract}
It is now clear from the many epidemiologic studies stating that a potential link exists between PD and CVD oral health care. Professionals can identify patients who are unaware of their risk of developing serious complications as a result of CVD and who are in need of CVD and those who need medical intervention. Accumulated evidence has strongly suggested that the long-term effects of periodontal diseases can be linked to more serious systemic conditions such as cardiovascular diseases (CVD) and diabetes. Especially a prevalence of coronary heart disease is found to be significantly increased in patients with periodontitis after adjusting the risk factors such as smoking, diabetes, and blood pressure. The purpose of this review is to provide basic information on periodontitis and cardiovascular diseases an association of these two conditions and current knowledge.

KEYWORDS: Periodontitis, Inflammation \& Cardiovascular Diseases
\end{abstract}

Received: Jan 16, 2018; Accepted: Feb 26, 2018; Published: Mar 15, 2018; Paper Id.: IJMPSAPR20185

\section{INTRODUCTION}

Periodontitis is an infectious and inflammatory disease which is caused by various micro-biomes present in the oral cavity and mainly in the subgingival crevice. It is characterized by the loss of attachment and destruction of the periodontium. Recent epidemiological studies clearly suggest that the periodontitis is one of the key risk factors for the onset of the cardiovascular disease $(\mathrm{CVD})^{1}$. Several studies have detected periodontal bacteria in the cardiovascular specimens. Evidence from the animal studies have demonstrated that there is an obvious association between the prevalence of periodontal pathogens, bacterial products, periodontitis and incidence of CVD related events $^{2}$. The continuous release of host inflammatory mediators may be a link between periodontitis and $\mathrm{CVD}^{3}$. Entry of the bacterial products from the periodontal lesions into the bloodstreams and the sequential induction and maintenance of the chronic inflammatory state also contribute to the progression in CVD.

\section{CORONARY ARTERY DISEASE AND PERIODONTITIS}

The chronic inflammation plays an important role in the development of coronary arterial disease(CAD). Periodontal disease is characterized by the release of different inflammatory mediators like MMPs at molecular levels, so an etiological relationship between periodontal disease and CAD is proposed. Humphrey et al4concluded that periodontal disease is associated with CAD through a meta-analysis. They illustrated that periodontal disease is a risk factor or marker for CAD and is independent of traditional CAD risk factors. Nakajima et al., 5 also revealed 
that periodontitis is associated with risk factors of CAD through endothelial cell dysfunction induced by either periodontopathic bacteria or their products. CRP concentrations were found higher among the patients with myocardial infarctions compared with those without the disease. Suzuki et al recently revealed that periodonto pathogens are associated with $\mathrm{CAD}$ through the findings of the higher titer of serum antibodies against Aggregatibacteractinomycetemcomitans in the blood samples of the patients associated with CAD along with the periodontal disease.

\section{PERIPHERAL ARTERIAL DISEASE AND PERIODONTITIS}

There are several papers pointing out to a relationship between periodontitis and peripheral arterial disease (PAD). Buhlinet al6associated this two disease by determining the plasma levels of some risk markers for PAD in cases of periodontitis. Statistical analysis significantly associates periodontitis and high levels of C reactive protein, fibrinogen, IL18, and antibodies against Heat shock proteins 65 and 70. Hence standard treatment strategies for periodontal disease induces systemic changes in several biochemical markers that reflect the risk for PAD. Chen et al in his study associated periodontal disease and PAD. They identified P. gingivalis, T. denticola, A. actinomycetemcomitans, and P. intermedia in the tissue specimens from the anastomotic sites of the distal bypass PCR. In this study, periodontopathogens are found in $52 \%$ of the atherosclerotic plaque specimens. Beurger's disease also showed a significant relationship to periodontitis. Iwai et al7in his study demonstrated that DNA of oral bacteria is detected in 13 of 14 arterial samples with Beurger's disease. They reported that Beurger's diseased patients had a high prevalence of periodontal disease with higher serum IgG antibodies against periodontopathic bacteria. They also found that the patients had higher titers serum anti-cardiolipin antibodies compared with healthy subjects.

\section{AORTIC ANEURYSMS AND PERIODONTITIS}

Abdominal aortic aneurysms (AAA) are a common and lethal disorder in the aging population. Inflammation with MMPs appears to play a critical role in the AAA development and progression. An increased MMP level has been observed in human aneurysm tissue specimens ${ }^{8}$. It is well known that MMPs play a vital role in periodontal disease. A Periodontopathic bacterium triggers the host inflammatory response, thereby secreting MMPs and degrades the extracellular matrix of periodontal tissues. Periodontal bacteria P. gingivalis was reported to be in high percentage in AAA specimens. Thus periodontopathic bacteria may play a role in the development of AAA.

\section{GENETIC SUSCEPTIBILITY CONTRIBUTING TO THE PERIODONTTITIS AND CVD}

Classical twin studies had shown that both complex diseases have a similar degree of heritability and that a significant fraction of the genetic factors accounting for this heritability is shared. Recent genome-wide association and large-scale candidate gene studies highlight the variations in $>50$ genes are associated with a premature CAD, while variations in only 4 genes showing nominally significant associations with aggressive periodontitis and/or chronic periodontitis have so far been identified. Remarkably, 3 of the PD loci $(75 \%)$ show shared associations with CAD (ANRIL/CDKN2B-AS1, PLG, CAMTA1/VAMP3), suggesting an involvement of common pathogenic mechanisms9.

\section{CONCLUSIONS}

In this brief article, there is a gist about the relationship between periodontal disease and cardiovascular disease. CVD can be avoided by routinely visiting to the dentist for oral hygiene. Scaling and root planning initially followed by the 
use of chlorhexeidene mouthwash and proper brushing of the teeth.

\section{REFERENCES}

1. Friedewald VE, Kornman KS, Beck JD, et al. The American Journal of Cardiology and Journal of Periodontology Editors' Consensus: periodontitis and atherosclerotic cardiovascular disease. Am J Cardiol2009; 104:59-68.

2. Herzberg MC, Meyer MW. Dental plaque, platelets, and cardiovascular diseases. Ann Periodontol1998; 3:151-60.

3. Desvarieux M, Demmer RT, Rundek T, et al. Periodontal microbiota and carotid intima-media thickness: the Oral Infections and Vascular Disease Epidemiology Study (INVEST). Circulation 2005; 111:576-82.

4. Humphrey LL, Fu R, Buckley DI, et al. Periodontal disease and coronary heart disease incidence: a systematic review and meta-analysis. J Gen Intern Med 2008; 23:2079-86.

5. Nakajima T, Yamazaki K. Periodontal disease and risk of atherosclerotic coronary heart disease. Odontology 2009;97:84-91.

6. Buhlin $K$, Hultin $M$, Norderyd $O$, et al. Risk factors for atherosclerosis in cases with severe periodontitis. $J$ ClinPeriodontol2009; 36:541-9.

7. Purobi Choudhury et al.,, Periodontal Disease and Pregnancy Outcome: A Correlative Study, International Journal of Dental Research \& Development (IJDRD), Volume 7, Issue 2, July - August 2017, pp. 1-6

8. Iwai T, Inoue Y, Umeda M, et al. Oral bacteria in the occluded arteries of patients with Buerger disease. J VascSurg2005; 42:107-15.

9. Davis V, Persidskaia R, Baca-Regen L, et al. Matrix metalloproteinase-2 production and its binding to the matrix are increased in abdominal aortic aneurysms. ArteriosclerThrombVascBiol1998; 18:1625-33.

10. G. Aarabi, T. Zeller, H. Seedorf, D. R. Reissmann, G. Heydecke, A.S. Schaefer, and U. Seedorf. Genetic Susceptibility Contributing to Periodontal and Cardiovascular Disease. Critical Reviews in Oral Biology \& Medicine 2017;1-6. 
